\title{
Editorial
}

\section{Steven Hunt}

The Journal of Classics Teaching is becoming a victim of its own success. Who would have known that the number of pages available in an online journal was actually finite? In its expansion over the last few years, the total number of pages allocated by CUP for the Classical Association has often been exceeded and an amicable settlement has had to be negotiated. Accordingly, after the last bumper edition, this autumn edition is slightly shorter, in order to compensate. And we have brought forward a change in the way in which we publish articles and book reviews. From this edition, 44, articles in the Journal of Classics Teaching will appear online more quickly, as they are accepted for publication, rather than waiting for a whole edition to be collated and published together. CUP, the Classical Association and the editor believe that this will streamline the publication process and will speed up the turnaround of articles so that they get out to the audience quickly. Twice a year, the articles that have been so far published will be digitally 'bound together' as a numbered edition of their own.

In the UK, schools have emerged from lockdown and classrooms returned to near normal (face masks in corridors, social distancing in communal areas, students in 'bubbles'). It feels that there is light at the end of a very long tunnel, or rather, series of tunnels. The examination system has creaked under the pressure and been overthrown, temporarily, but the impact has been keenly felt by teachers themselves who have had to administer a whole set of examinations, tests and forms of assessment to satisfy their schools, the Department for Education, the examination boards and Ofqual. Lockdown has shown the problems which can happen when national student assessment is almost entirely carried out by sudden-death linear examinations, with no modularisation, and no coursework to provide evidence of student achievement. Can we go back to where we were? How much the overwrought UK examination system can be sustained has been under some scrutiny for some years now. As a measurement of student achievement, a means for ranking schools, and as a target for school self-improvement in which every 'winner' must be matched against a 'loser' in the eternal race that is Progress 8 , the GCSE has rather lost its way as a school-leaving certificate when no-one leaves full-time education at 16 any more. Even the architect of the GCSEs, Lord Baker, considers their time has come (The Independent, 2020). But what to replace them with? As for A levels in classical subjects, schools continue to struggle to attract viable classes: the lack of funds for small classes, the decoupling of AS from A levels, and the march of STEM in the popular imagination as the route to wealth and success in later life means they barely stand a chance (Hunt \& HolmesHenderson, 2021). The present Secretary of State for Education, Gavin Williamson, declared his satisfaction about how ' $[\mathrm{t}]$ he record number of people taking up science and engineering demonstrates that many are already starting to pivot away from dead-end courses that leave young people with nothing but debt' (Conservative Home, 2021),

Author of correspondence: Steven Hunt, E-mail: sch43@cam.ac.uk

Cite this article: Hunt S (2021). Editorial. Journal of Classics Teaching, 22, 83-85. https:// doi.org/10.1017/S2058631021000209 echoing (though perhaps not deliberately) one of his predecessors, Charles Clarke, who was similarly notoriously dismissive of 'dustier subjects' (The Guardian, 2003). How this negativity may sit with a classicist Prime Minister, who has in the past supported the reintroduction of Latin and Greek and non-linguistic classical subjects into the state sector both through personal involvement and through the initiation of educational policies favourable to them, is an interesting consideration. Some teachers have decided not to wait. We see a team of them, from state-maintained and independent schools, working together on an alternative to the Classical Greek GCSE, because the Ofqual-contrived GCSE is almost impossible to deliver in the time available to them in their schools and yet they do not want Greek to die. There are lessons surely to be learned from the thinking behind and development of this qualification which might fit the development of others - where the qualification is a realistic target in schools for the students sitting in them, not a creation by a government department fixated, as it seems, on an ideal, where funding, teachers and time allocation are abundant, and which are used for school comparability purposes as much as for recognition of individual students' achievement. Perhaps more so. If classical subjects are to thrive and even expand everywhere, but especially in the state sector (as the Department for Education probably intends), we need more, perhaps teacher-designed, qualifications that are practicable in the classrooms of today (Hunt, 2021).

Meantime, this edition of the Journal of Classics Teaching contains a number of thought-provoking articles, several of which respond to the current interest in qualifications. Arlene HolmesHenderson and Bella Watts fastidiously research the complex world of UK university entrance qualifications for classical subjects: What grades are needed to study Classical subjects at UK universities? Alberto Regagliolo contributes a study of a STEM-based introduction to the ancient Romans for primary school students in Spain: Roman Numerals in Spanish Primary Education. Polyxeni Poupounaki-Lappa, Tzortzina Peristeri and David Coniam introduce a proposal for a new type of examination for Classical Greek: Towards a Communicative Test of Reading and Language Use for Classical Greek. David Hodgkinson considers the future direction of classics in schools: Classics for the Future: A Time for Reflection. Sam Baddeley provides a very helpful description of experiences and thoughts on lessons learned from online teaching at his school: Online teaching: a reflection. By the time this journal is published, it will be getting on for a new school year. What lies ahead, no-one can foretell. Has a tide turned?

\section{Articles}

Holmes-Henderson, A. and Watts, B. What grades are needed to study Classical subjects at UK universities.

Regagliolo, A. Roman Numerals in Spanish Primary Education.

Poupounaki-Lappa, P., Peristeri, T. and Coniam, D. Towards a Communicative Test of Reading and Language Use for Classical Greek.

Hodgkinson, D. Classics for the Future: A Time for Reflection. Baddeley, S. Online teaching: a reflection. 


\section{Book Reviews}

Bartsch (S.) Vergil: The Aeneid. A New Translation. Lucy Angel.

Berry (D.) Cicero's Catilinarians. Evan Dutmer.

Carter (A.) Selections from Virgil's Aeneid, Books 7-12. A Student Reader. Jo Lashly.

Collins (M.) and Stearns (P.) Why Study History? Barry Knowlton.

Eaton (J.) Leading the Roman Army. Soldiers and Emperors 31 BC-AD 235. Danny Pucknall.

Fontaine (M.) Vincent Obsopoeus: How to Drink. A Classical Guide to the Art of Imbibing. Gary Vos.

Goldsworthy (A.) Philip \& Alexander. Kings and Conquerors. Danny Pucknall.

Hands-Up Suburani Book. Emma Wall.

Radice (K.), Cheetham (A.), Kirk (S.), Lord (G.) De Romanis Book 1: dei et deae. Emma Wall.

Haynes (N.) Pandora's Jar. Women in the Greek Myths. Lucy Angel.
Jackson (R.) The Roman Occupation of Britain and its Legacy. Giles Dawson.

Mackenzie (C.) A Latin Lexicon. An Illustrated Compendium of Latin Words and English Derivatives. Emma Wall

Momigliano (N.) In Search of the Labyrinth. The Cultural Legacy of Minoan Crete. Erini Apanomeritaki

Morgan (L.) Ovid - a Very Short Introduction. Giles Dawson

Womack (P.) The Arrow of Apollo. Hilary Meyrick-Long

Many articles for the Journal of Classics Teaching start up as conference pieces or teach-meet talks or presentations at staff meetings. The editor always welcomes interesting or novel pieces, as well as articles which simply describe good teaching practice or events or things of interest to other teachers. Readers should feel confident to submit articles in the usual way to the Classical Association.

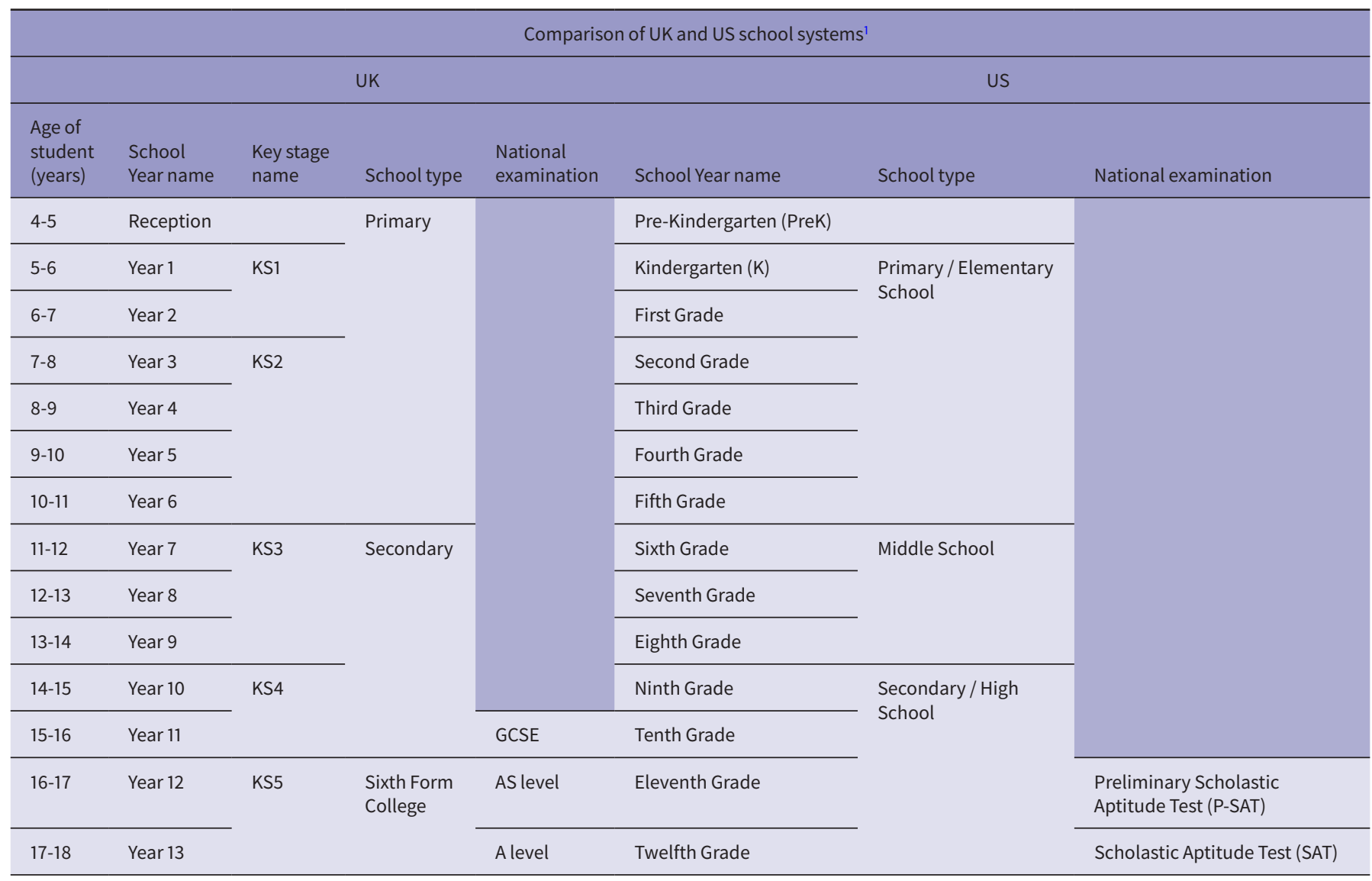

\section{Submitting an article to JCT}

The Journal of Classics Teaching is the leading journal for teachers of Latin, Ancient Greek, Classical Civilisation and Ancient History in the UK. It originated as the voice of the Joint Association of Classical Teachers in 1963 under the title Didaskalos, being renamed Hesperiam over the years, and finally JCT. It has a broadly-based membership including teachers in the primary, secondary and tertiary education sectors. JCT welcomes articles, news and reports about Classics teaching and items of interest to teachers of Classics both from the UK and abroad. If you wish to submit an article, it should be sent to the JCT Editor, c/o the Classical Association canews@classicalasociation.org.

Articles are welcome on classroom teaching practice or on studies about the teaching and learning of Classics in the UK and abroad and should be up to 7,000 words. There should be clear pedagogical or academic content. News and reports of events of general interest to teachers of Classics should be between 1,000 and 2,000 words.

All articles should be submitted in Arial 12 point, 1.5 line-spaced and with non-justified margins, and should include the author's name and some biographical details. Images, graphs, diagrams and tables should be submitted separately as jpgs or pdfs as appropriate, with an indication in the text where they should be included. In general, JCT prefers references to conform to the author-date referencing style of the American Psychological Association (APA). The editor can supply further details of this referencing style if desired. Please ensure that you have permission to reproduce photographs of pupils or the relevant copyright for images, or give details of the origin of the image used. Recent editions of the journal give a guide to the layout of articles. 
After submission by the author, the article may be submitted to peer review. The Editor reserves the right to suggest any changes that are felt are needed to be made and makes minor corrections. If major changes are thought to be needed, the author will be asked to rewrite the section which needs changing. Once accepted, the author is assumed to have assigned the right to JCT to distribute the publication electronically. Articles are copyrighted by their respective authors, but if published after electronic appearance, JCT will be acknowledged as the initial place of publication.

For 50 years JCT and its predecessors were published in hard copy and made available to members of the Joint Association of Classical Teachers. From 2015 JCT has been available freely online, generously supported by the Classical Association. Back issues of hard copies of JCT are sometimes available from the CA Shop and as downloadable pdfs of individual articles freely online via the Association for Latin Teaching website www.arlt.co.uk.

\section{Note}

1 The comparison table is taken from Teaching Classics with Technology, published by Bloomsbury Academic (Natoli \& Hunt, 2019).

\section{References}

Conservative Home. (2021) Gavin Williamson: Skills, jobs and freedom. My priorities for this week's Queen's Speech - and the year ahead. Web Blog. Available online: https://www.conservativehome.com/platform/2021/05/ gavin-williamson-skills-jobs-and-freedom-my-priorities-for-this-weeksqueens-speech-and-the-year-ahead.html (accessed 20 May 2021).

Hunt, S. (2021) Where have all the exams gone? Classics Matters, Spring 2021. Available online: https://classicsforall.org.uk/news-and-events/classicsmatters-newsletter/classics-matters-spring-2021 (accessed 20 May 2021).

The Guardian. (2003) Will Charles Clarke have his place in history? Available online: https://www.theguardian.com/uk/2003/may/10/highereducation. politics (accessed 20 May 2021).

The Independent. (2020) State and private schools in 'movement' to scrap GCSEs Available online: https://www.tes.com/news/state-and-privateschools-movement-scrap-gcses (accessed 20 May 2021). 